\title{
Multi-focused psychosocial residential rehabilitation interventions improve quality of life among cancer survivors: a community-based controlled trial
}

\author{
Xuefen Chen ${ }^{1,2}$ (D) Xiaohuan Gong ${ }^{1}$, Changhong Shi ${ }^{1}$, Li Sun ${ }^{1}$, Zheng Tang ${ }^{1}$, Zhengping Yuan ${ }^{3}$, Jiwei Wang ${ }^{1 *}$
} and Jinming $Y u^{1 *}$

\begin{abstract}
Background: Even though multi-focused psychosocial residence rehabilitation intervention (MPRRI) programs are widely implemented by the Shanghai Cancer Rehabilitation Club, these programs have not been rigorously evaluated. In this study, we evaluated the effects of a 21-day MPRRI program, on the quality of life (QoL) among cancer survivors.

Methods: A total of 388 cancer patients were enrolled to either receive the 21-day MPRRI $(n=129)$ intervention or a waiting-list comparison (WLC) intervention $(n=259)$. The intervention group was offered community-based 21-day MPRRI program, combining supportive-expressive group, cognitive-behavioral therapy, and Guolin Qigong. QoL was measured using the European Organization for Research and Treatment Quality of Life Version 3 Questionnaire. Multivariable linear models were used to compare changes in QoL values between the two groups.

Results: After adjustment for the QoL score and other covariates at baseline, there was no significant difference in global health status (mean $=3.8,95 \% \mathrm{Cl}-1.3-9.0, P=0.14$ ) between the two groups after 6 months intervention. While compared with the WLC group, the intervention group showed significant improvements in the QoL score (all $P<0.05)$; however, there were no clinically relevant changes in subscales including emotional functioning ( $E S=0.58)$, cognitive functioning $(E S=0.53)$, pain $(E S=0.52)$, physical functioning $(E S=0.36)$, and insomnia $(E S=0.30)$.
\end{abstract}

Conclusions: These preliminary results suggest the MPRRI program is both feasible and acceptable intervention for cancer survivors in community settings and is effective in significant improving QoL above.

Keywords: Cancer survivors, Psychosocial intervention, Rehabilitation, Quality of life

\section{Background}

Cancer is the leading cause of mortality in China, accounting for nearly two million deaths each year and approximately one-quarter of all deaths in the country. At the same time, the number of cancer survivors in China is continuously increasing due to advances in early cancer

\footnotetext{
*Correspondence: jiweiwang@fudan.edu; jmy@fudan.edu.cn ${ }^{1}$ Key Lab of Public Health Safety of Ministry of Education and Key Lab of Health Technology Assessment of Ministry of Health, School of Public Health, Fudan University, No. 130 Dongan RD, Xuhui District, Shanghai Zip code: 200032, China

Full list of author information is available at the end of the article
}

diagnosis and treatment [1-4]. Cancer has been documented as the cause of considerable psychological strain for cancer survivors and their families. Quality of life (QoL) is affected by the need to face a chronic and lifethreatening disease and the demands and complications of repeated, lengthy, and often invasive therapies [5-7]. The emotional impact of a cancer diagnosis and treatment is devastating, characterized by shock, anxiety, and depression, and affects daily living $[8,9]$.

Cancer survivors have a number of psychosocial needs, such as physical, psychological, and social aspects of care and treatment of the disease. These include treatment 
options and decision-making, the stress on others, sharing the illness experience and connecting with other cancer survivors, and gaining a sense of control [10]. Numerous psychosocial interventions have been developed to evaluate these needs. A psychosocial intervention can be defined as any treatment intended to address the psychological, social, spiritual needs, or any combination of these rather than the disease itself [11]. These interventions commonly incorporate a number of different components but can generally be classified as education, social supportive-expressive group development, guided imaginary, music therapy, cognitive-behavioral techniques, and counseling [12].

In China, after inpatient medical treatment, community health service centers often provide all follow-up care [13], but such care, including psychosocial care, has been shown to be inadequate [14]. Cancer self-help rehabilitation groups are considered one of the most promising aspects of cancer psychosocial interventions, which are multi-factorial programs covering several aspects of well-being and are conducted under real-world conditions, rather than tightly controlled research projects $[15$, 16]. However, it is not common in China compared with Western countries, and those that were available were ineffective until the first cancer self-help organization, the Shanghai Cancer Rehabilitation Club (SCRC), was formed in 1989. The SCRC is an important survivorship improvement organization, and its goal is to support cancer survivors throughout their care with multi-focused psychosocial interventions.

Although multi-focused psychosocial residence rehabilitation intervention (MPRRI) programs are widely implemented, the effect of such interventions has not been rigorously evaluated. The aim of this study was to evaluate the effects of a 21-day MPRRI program on the QoL of cancer survivors.

\section{Methods}

\section{Recruitment and study participants}

Convenience samples of cancer survivors were collected in Shanghai, China by the SCRC. Participants were primarily recruited through pamphlets and posters around their medical care facilities. The inclusion criteria were: (1) participants had a clinical diagnosis of cancer and showed interest to participate; (2) had completed conventional medical care at a hospital and were medically stable; (3) were between 18 and 70 years old and had an expected survival time of over 1 year; (4) Chinese residents who were able to read, speak, and write Chinese; and (5) had normal cognitive and sensory functions with no psychological condition that might potentially hamper compliance with informed consent.

\section{Intervention groups}

In this study, a total of 388 study participants were enrolled into either a waiting-list comparison (WLC) group $(n=259)$ or the MPRRI group $(n=129)$ (November 2013 to January 2015). The WLC group received standard follow-up care as a control, which consisted of health lectures every month and communication with healthcare staff. The intervention group received a multi-focused intervention, consisting of 6 components.

\section{(1) Supportive-expressive group}

Study participants with same or similar types of cancer were divided into groups and asked to develop a team name and anti-cancer slogan, attend group meetings that were facilitated by SCRC staffs, and focus on expression of emotions in a supportive group environment to reduce negative emotions and promote psychological adjustment [17].

\section{(2) Relaxation training and guided imagery}

Study participants participated in morning meditation for half an hour and listened to music with guided meditation $C D$ tracks that were designed to promote familiarity with relaxation and visualization. Instructions were provided for CD use, focused breathing, and relaxation techniques. Participants were encouraged to imagine themselves in a peaceful, serene, safe, and secure personal place to rest and let go of their anxiety, worries, or concerns and emerge from their scenario with a sense of feeling refreshed and recharged [18]. This feeling state image of a pleasant and safe scene focused on feelings of peace, calm, and relaxation.

\section{(3) Art and music therapy}

Art therapy here included music therapy interventions, numerous types of art therapy, and dance/movement therapies [19]. Patients met with a music therapist (a board certified music therapist) for nine 50-min sessions over the course of 21 days. During the session, participants worked in collaboration with rhythmic drumming in a circle under the guidance of the music therapist, who encouraged the participants to release their anxious and tense emotions and help them integrate into one team to facilitate communication with each other [20]. Additionally, patients learned to sing songs, such as "Grateful Heart" with sign language "The Song of the Rehabilitation School" and "Let Love Move," and dance.

\section{(4) Cognitive-behavioral therapy (CBT)}

CBT was provided to groups of six to ten individuals for 90 min twice a week for 3 weeks. The therapy 
included the following validated strategies: stimulus control, confidence restriction, cognitive therapy, and relaxation training. This training was formatted to be consistent with a cognitive-behavioral problem-solving therapy protocol for individual cancer patients. CBT aims to enable participants to effectively solve their personal problems associated with cancer. To this end, they learned to apply self-management skills in striving for personal goals (e.g., in work, household, hobbies, physical activity, family relationships, and social contacts) [21, 22]. Generalization to daily life during and after rehabilitation was facilitated by practicing activities during sessions and by homework assignments (maximally 30 min weekly).

\section{(5) Psycho-education and counseling}

At the beginning of rehabilitation camp patients watched lectures from Professor Zhaoyou Tang, a famous surgical oncology expert in China, and regularly received some specific topics of health education, such as nutrition education and diet guidance. Many interventions include an educational component to satisfy patients' needs for comprehensive information about their disease, treatment options, and potentially helpful coping strategies $[23,24]$.

\section{(6) Guolin Qigong}

Study participants underwent $2.5 \mathrm{~h}$ of Guolin Qigong training once a day for 5 days a week. This training, a type of aerobic exercise, was incorporated to elicit improvements in aerobic capacity [25]. Additionally, the Guolin Qigong training aims to bring the body and mind into balance and to relieve the residual side effects of clinical treatment. This technique places emphasis on meditation and coordinated breathing, together with slow and smooth movements [26]. An instructor and an assistant instructor supervised study participants during each training session.

\section{QoL scales}

QoL was measured by the simplified Chinese version of the European Organization for Research and Treatment quality of life version 3 questionnaire (EORTC QLQC30) [27]. The EORTC QLQ-C30 core questionnaire contained five functional scales (physical, role, cognitive, emotional, and social), three symptom scales (fatigue, pain, and nausea and vomiting), a global health status (GHS), a number of single items assessing additional symptoms commonly reported by cancer patients (dyspnea, appetite loss, insomnia, constipation, and diarrhea), and the financial impact of the disease. A high score on the functional scale, the global health status, or overall QoL represents a high or healthy status or a high QoL, whereas a high score for the symptom scale represents a high level of symptomatology or problems. The scoring of the EORTC QLQ-C30 items was performed as stipulated in the EORTC scoring manual [28].

\section{QoL measurements}

Assessments were made at baseline, at 4-week, and 6-month after the intervention in the MPRRI group and at baseline and 4-week after the intervention for the WLC group. The baseline assessment consisted of questionnaires to measure demographic and medical variables, physical activity, and QoL. Similarly, the 4-week and 6-month follow-up questionnaires assessed physical activity and QoL.

\section{Covariates}

We additionally assessed the effects of behavioral and lifestyle factors among intervention groups. The behavioral and lifestyle factors we examined included dietary habits (vegetable and fruit consumption in the past 7 days, having vs. skipping breakfaster each day), smoking status (characterized as current, former, or never smoking), drinking alcohol (including beer, red wine, and white wine consumption as a binary variable) and sleeping status (need to take medicine or not). Additionally, study participants provided information regarding physical activity, such as self-reporting the average time per week spent on which kind of physical activity in the past 4 weeks. Physical activity was defined as those who participate in moderate activities for $30 \mathrm{~min}$, such as jogging, running, bicycling, swimming, table tennis, Qigong, and Taichi. Measurement of physical activity was recorded as binary (Yes or No), binary frequency ( $\geq 5$ times/week or $<5$ times/week), and continuous time (hours/week).

\section{Statistical analysis}

The pre-specified primary QoL outcome was GHS on the EORTC QLQ-c30 to test the hypothesis that participants in the 21-day MPRRI group would have better QoL compared with participants in WLC group. Univariable analyses were performed to assess adherence to the assumptions of normality and equal variance, as well as for the detection of outliers. Fisher's exact or $\chi^{2}$ tests were conducted on categorical variables, including sex, marital status, monthly household income per capita, smoking status, cancer type, and medical treatment. Wilcoxon rank test or $t$ tests were performed on continuous variables, including age, body mass index (BMI), and years since cancer diagnosis, highest educational achievement, and alcohol consumption.

Multivariable linear regression was used to determine the difference of QoL subscales between two groups at 6 months from baseline. Covariates included sex, age, 
BMI, education level, monthly household income per capita, cancer type, time since cancer diagnosis, and behavioral and lifestyle factors at baseline.

To explore the effect within groups, we also fit a multilevel linear growth model (MLGM) [29] for subscales. Mean GHS scores and corresponding 95\% confidence intervals (CIs) were estimated.

Furthermore, generalized estimating equations (GEE) were used to analyze the change in behavior and lifestyle factors between two groups. Effect sizes (ES) were calculated according to Cohen as indices measuring the magnitude of a treatment effect. An ES $<0.2$ reflects "no effect," $0.2 \leq \mathrm{ES} \leq 0.5$ reflects "small effect," $0.5 \leq \mathrm{ES} \leq 0.8$ reflects "moderate effect," and $E S \geq 0.8$ reflects "large effect." [30].

All statistical analyses were performed using SAS version 9.2 (SAS Institute Inc., Cary, NC, US). P values $<0.05$ were considered significant.

\section{Results}

\section{Baseline characteristics}

An overview of number of patients enrolled in the two groups and lost to follow-up is provided in Fig. 1. The MPRRI group completed $93.02 \%$ at 4-week, $86.82 \%$ at 6 -month, and the WLC group completed $95.75 \%$ at 6-month from baseline.

Table 1 shows participants' baseline characteristics. The groups were balanced in terms of sociodemographic factors, behavior and lifestyle factors, and medical variables. The mean time since initial diagnosis years of participants in the MPRRI group ( $2.05 \pm 1.50$ year) was not significantly different than the mean from WLC group $(2.32 \pm 1.63$ year, $P=0.09)$. Lung cancer accounted for $23.3 \%$ and $21.2 \%$ of the total number of initial cancer diagnoses in the 21-day MPRRI group and WLC group, and breast cancer accounted for $31.8 \%$ and $25.9 \%$ respectively. There was no significant difference in cancer type between two groups $(P=0.63)$. However, WLC participants were less educated than participants in the 21-day MPRRI group $(P<0.0001)$.

\section{Quality of life associations (1) GHS modeling}

After adjustment for the QoL score and other covariates at baseline, difference in GHS score between two groups at each of 6-month was not statistically significant $(P=0.14)$ and larger than 10 -points, which are considered to be clinically relevant changes in the EORTC QLQ [31] (Table 2). The difference was 3.8 (95\% CI, - 1.3-9.0), indicating a greater score in the 21-day MPRRI group, but it was not beyond the 10-ponit threshold for clinical significance. Figure 2 shows the mean GHS scores estimated according to the MLGM model and the corresponding
95\% CIs. In both groups, the mean GHS scores tended to improve over time. While GHS $(E S=0.27)$ showed a small treatment effect.

\section{(2) Other scales}

Among the other scales of the EORTC QLQ-C30, the 21-day MPRRI intervention group showed significant improvements over the WLC group $(P<0.05)$ in emotional functioning ( $\mathrm{ES}=0.58)$, cognitive functioning $(\mathrm{ES}=0.53)$, pain $(\mathrm{ES}=0.52)$, physical functioning $(E S=0.36)$, and insomnia $(E S=0.30)$ (Table 2), with the former 3 subscales representing moderate treatment effect. These improvements, however, did not reach the predetermined minimal clinically important difference of 10 points. No significant differences were observed for scores on the other scales (role functioning, social functioning, fatigue, nausea or vomiting, dyspnea, appetite loss, constipation, diarrhea, financial difficulties).

\section{(3) Intra-group effect}

Improvements within the 21-day MPRRI group and GHS were both significant $(P<0.0001)$ and clinical improvement (estimated mean difference $=11.2,95 \% \mathrm{CI}$ 7.0-15.5) at 4-week from baseline, but not continuing to the 6-month values. Physical functioning, emotional functioning, cognitive functioning, and pain were significant $(P<0.05)$ at 4 -week from baseline and continued until 6-month follow-up, except for physical functioning (Table 3). In contrast, the WLC group exhibited significant declines from baseline in physical functioning, emotional functioning, cognitive functioning $(P<0.0001)$, insomnia $(P<0.01)$, and pain $(P<0.05)$.

\section{Changes in behavior and lifestyle factor between two groups}

Using GEE to analyze the changes in behavior and lifestyle factors between two groups, we observed a significant interaction between time and group for not only the proportion of physical activity participation $(\mathrm{OR}=2.042$, 95\% CI 1.139-3.663) but also in the frequency of physical activity (OR $=1.757,95 \%$ CI 1.330-2.332) (Table 4). Additionally, the change in the amount of time spent in physical activity from baseline to 6 months between groups was found to be significant (mean difference $=4.54,95 \%$ CI 3.19-5.90) $($ Table 4).

\section{Discussion}

In this study, cancer survivors in the 21-day MPRRI group exhibited improvements in most of the subscales of QoL, whereas the QoL of the participants in WLC group continuously declined. Moreover, the mean difference of subscales from baseline to 6-month follow-up in 


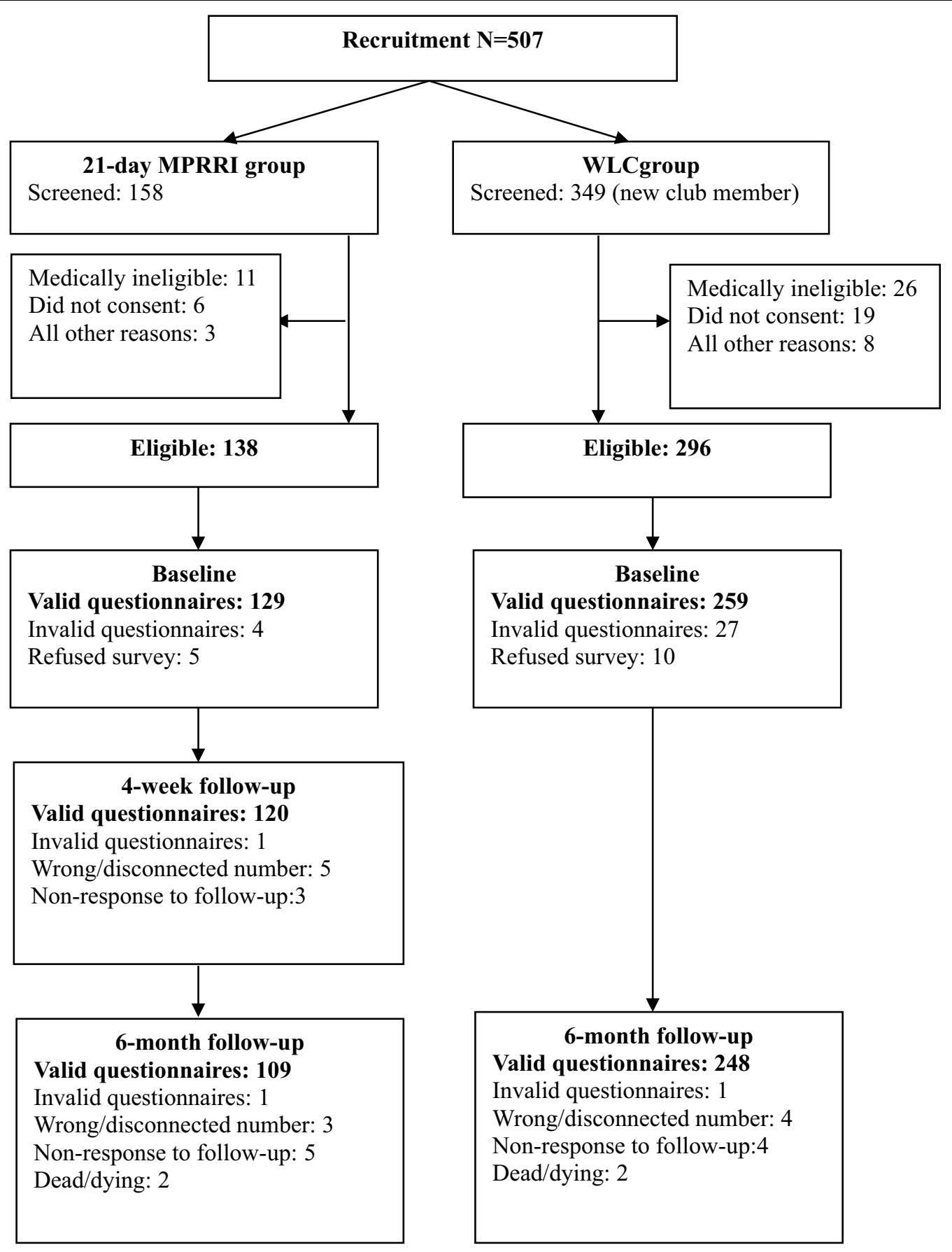

Fig. 1 Participant flow chart

the 21-day MPRRI group showed greater advancement than that of the WLC group.

The SCRC offered continuous training courses for 21 days in one session on how to confront the disease, how to deal with emotions, how to interact with others, and how to plan for the future. Furthermore, the provision of factual information, development of a sense of community, transformation in terms of personal change and spiritual growth, and a feelings of empowerment at individual and community levels were also considered important. Possible mechanisms of intervention include maximum possible acquisition of various support care and resources. 
Table 1 Sociodemographic, behavior and lifestyle factors, and clinical data at baseline for the intervention groups

\begin{tabular}{|c|c|c|c|}
\hline Variables & 21-day MPRRI & WLC-group & $P$ \\
\hline Age, mean (SD), years & $57.0(7.5)$ & $57.9(7.2)$ & 0.2296 \\
\hline BMl, mean (SD), kg/m² & $23.4(3.4)$ & $23.1(3.1)$ & 0.4154 \\
\hline Gender, n (\%), female & $96(74.4)$ & $173(66.8)$ & 0.1250 \\
\hline \multicolumn{4}{|l|}{ Marital status, n (\%) } \\
\hline Married/with partner & $115(89.2)$ & $227(87.6)$ & \multirow[t]{2}{*}{0.6662} \\
\hline Single/widowed/divorced & $14(10.8)$ & $32(12.4)$ & \\
\hline \multicolumn{4}{|l|}{ Education, n (\%) } \\
\hline Compulsory school & $31(24.0)$ & $107(41.3)$ & \multirow[t]{3}{*}{0.001} \\
\hline Apprenticeship/technical college & $55(42.6)$ & $100(38.6)$ & \\
\hline University & $43(33.3)$ & $52(20.1)$ & \\
\hline \multicolumn{4}{|l|}{ Monthly household income per capita (Yuan, RMB) } \\
\hline$\leq 2000$ & $22(17.1)$ & $55(21.2)$ & \multirow[t]{3}{*}{0.3636} \\
\hline $2001-4000$ & $87(67.4)$ & $175(67.6)$ & \\
\hline$\geq 4001$ & $20(15.5)$ & $29(11.2)$ & \\
\hline Current Smoker, n (\%) & $3(2.3)$ & $8(3.1)$ & 0.9187 \\
\hline Drinking alcohol in past 4-week, n (\%) & $11(8.5)$ & $11(4.3)$ & 0.0859 \\
\hline \multicolumn{3}{|l|}{ Diagnosis, n (\%) } & \multirow[t]{6}{*}{0.6271} \\
\hline Lung cancer & $30(23.3)$ & $55(21.2)$ & \\
\hline Breast cancer & $41(31.8)$ & $67(25.9)$ & \\
\hline Digest tract cancer ${ }^{\mathrm{a}}$ & $32(24.8)$ & $70(27.0)$ & \\
\hline Gynecological cancer $^{b}$ & $7(5.4)$ & $17(6.6)$ & \\
\hline Other type ${ }^{c}$ & $19(14.7)$ & $50(19.3)$ & \\
\hline Time since initial diagnosis, mean (SD), years & $2.05(1.50)$ & $2.32(1.63)$ & 0.0941 \\
\hline \multicolumn{4}{|l|}{ Medical treatment, n (\%) } \\
\hline Surgery & $107(82.9)$ & $202(78.0)$ & 0.2537 \\
\hline Radiotherapy & $38(29.5)$ & $66(25.5)$ & 0.4050 \\
\hline Chemotherapy & $101(78.3)$ & $189(73.0)$ & 0.2557 \\
\hline Traditional Chinese medicine & $87(67.4)$ & $154(59.5)$ & 0.1268 \\
\hline
\end{tabular}

Table 2 Summary of the Quality-of-Life Results

\begin{tabular}{|c|c|c|c|c|c|c|c|}
\hline \multirow[t]{2}{*}{ Subscales } & \multicolumn{2}{|l|}{ WLC } & \multicolumn{2}{|l|}{ 21-day MPRRI } & \multicolumn{3}{|c|}{$\begin{array}{l}\text { Pre to 6-month between-group } \\
\text { change } 21 \text { day-MPRRI with WLC }\end{array}$} \\
\hline & Baseline $(n=259)$ & 6-month $(n=248)$ & Baseline $(n=129)$ & 6-month $(n=109)$ & $\Delta(95 \% \mathrm{Cl})$ & $P$ & ES \\
\hline Global health status & $61.1 \pm 22.7$ & $63.3 \pm 23.2$ & $58.2 \pm 22.8$ & $66.7 \pm 19.9$ & $3.8(-1.3,9.0)$ & 0.1437 & 0.2720 \\
\hline Physical functioning & $82.7 \pm 12.8$ & $80.2 \pm 15.4$ & $78.9 \pm 15.0$ & $80.8 \pm 13.0$ & $3.1(0.3,6.4)$ & 0.0332 & 0.3628 \\
\hline Emotional functioning & $84.9 \pm 17.1$ & $82.3 \pm 19.3$ & $77.1 \pm 22.7$ & $83.5 \pm 16.4$ & $6.0(2.5,9.5)$ & 0.0009 & 0.5794 \\
\hline Cognitive functioning & $84.4 \pm 16.2$ & $81.4 \pm 16.3$ & $74.2 \pm 19.4$ & $79.7 \pm 18.8$ & $3.5(0.1,6.9)$ & 0.0443 & 0.5297 \\
\hline Pain & $12.9 \pm 15.7$ & $15.3 \pm 17.9$ & $19.9 \pm 22.4$ & $12.3 \pm 14.5$ & $-6.0(-9.7,-2.3)$ & 0.0015 & 0.5171 \\
\hline Insomnia & $19.6 \pm 24.1$ & $24.0 \pm 26.3$ & $26.4 \pm 29.7$ & $22.5 \pm 28.8$ & $-5.3(-10.2,-0.4)$ & 0.0346 & 0.3011 \\
\hline
\end{tabular}

\section{Emotional support}

Cancer survivors experience physical, psychological, mental, and social problems beginning with their diagnosis [8, 9]. According to research reports, emotional support for cancer patients living in China is heavily dependent on family and otherwise relatively 


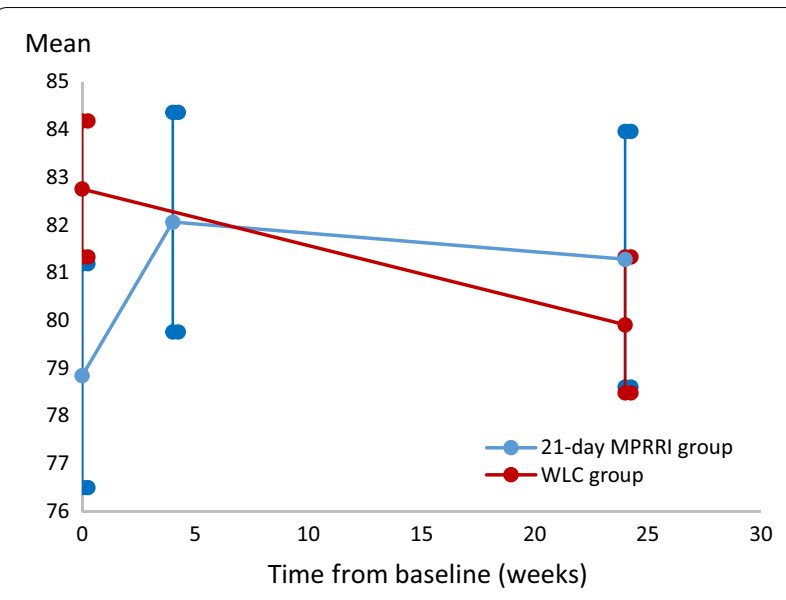

Fig. 2 Mean global health status (GHS) scores and corresponding 95\% confidence intervals (Cls) were estimated using the model

limited [32]. Additionally, family caregivers also experience great stress $[17,33]$. During this intervention, cancer patients can receive further emotional support from SCRC staff and from cancer survivors with similar experiences.

\section{Information support}

A lack of information may produce feelings of uncertainty and can impede decision-making [34, 35]. Patient care following cancer treatment and quality of life could be improved by providing ongoing education about lifestyle factors related to cancer risk, disease surveillance, and resources for treating and coping with cancer [36] and help develop community cancer support care to meet cancer survivors' needs for accurate information [35]. In the 21-day MPRRI group, information support from both peer-patients and clinical experts within the same type of cancer in the form of communications seminars was found to help cancer survivors address their dilemmas and cope with their difficult situation.

\section{Social recognition}

Most cancer patients suffered from discrimination, including both feelings of discrimination and their actual experience. If they are discriminated against by people around them, they might become more vulnerable with low self-esteem [37, 38]. The participants will get much social recognition by from SCRC, as self-support service, even after intervention.

Although participants had no significant improvements in the GHS/QL, there were improvements in both the functioning (emotional, cognitive) and symptom (pain)

Table 3 Effects of QoL within the two groups' cancer survivors among three assessments

\begin{tabular}{lccc}
\hline & Pre to 4-week change within 21-day & Pre to 6-month change within 21-day & $\begin{array}{c}\text { Pre to 6-month } \\
\text { change within WLC }\end{array}$ \\
\hline Physical functioning & $3.2(-1.2,2.8)^{* *}$ & $2.4(-0.2,5.1)$ & $-2.8(-4.7,-1.0)^{* *}$ \\
Emotional functioning & $8.8(5.5,12.1)^{* * *}$ & $6.7(3.7,9.7)^{* * *}$ & $-3.0(-5.1,-0.9)^{* *}$ \\
Cognitive functioning & $4.6(1.7,7.5)^{* *}$ & $5.5(2.6,8.4)^{* *}$ & $-3.1(-5.1,-1.2)^{* *}$ \\
Global health status & $11.2(7.0,15.5)^{* * *}$ & $8.4(3.8,13.0)^{* *}$ & $2.2(-1.1,5.4)$ \\
Pain & $-5.8(-9.1,-2.5)^{* *}$ & $-7.6(-10.9,-4.2)^{* * *}$ & $2.6(0.3,4.9)^{*}$ \\
Insomnia & $-0.8(-4.6,3.1)$ & $-3.2(-7.5,1.0)$ & $4.4(1.5,7.3)^{* *}$ \\
\hline
\end{tabular}

$* * *<0.0001, * *<0.01, * 0.05$

Table 4 Comparison of the change in behavior and lifestyle factors between the two groups (n, (\%))

\begin{tabular}{|c|c|c|c|c|c|c|}
\hline & \multicolumn{2}{|c|}{ WLC-group } & \multicolumn{3}{|c|}{ 21-day MPRRI group } & \multirow[t]{2}{*}{$P$ value } \\
\hline & Baseline & 6-month & Baseline & 4-week & 6-month & \\
\hline \multicolumn{7}{|l|}{ Physical activity } \\
\hline Participate in & $166(64.1)$ & $192(80.0)$ & $101(78.3)$ & 115 (95.8) & 107 (95.5) & 0.0166 \\
\hline$\geq 5$ times/week & $99(38.2)$ & $110(45.8)$ & $63(48.8)$ & $90(75.0)$ & $88(78.6)$ & $<0.0001$ \\
\hline Time(hours/week), mean (SD) & $3.7(5.4)$ & $4.8(5.4)$ & $5.2(6.7)$ & $10.8(6.8)$ & $10.5(8.4)$ & $<0.0001$ \\
\hline Have breakfast everyday & $252(97.3)$ & $229(95.4)$ & $124(96.1)$ & $117(97.5)$ & $111(99.1)$ & 0.0751 \\
\hline Intake fruits everyday & $192(74.1)$ & $177(73.7)$ & $106(82.2)$ & $101(84.2)$ & $95(84.8)$ & 0.5653 \\
\hline Vegetable intake $\geq 250 \mathrm{~g} /$ day & $100(38.6)$ & $97(40.4)$ & $65(50.4)$ & $58(48.3)$ & $66(58.9)$ & 0.3942 \\
\hline Sleep medication & $68(26.3)$ & $65(27.1)$ & $42(32.6)$ & $30(25.0)$ & $28(25.0)$ & 0.0814 \\
\hline
\end{tabular}


scales after the intervention, which suggests that the rehabilitation course for cancer survivors' overall QoL, improvement in functional areas, and symptom relief is effective.

Cognitive and emotional dysfunction in cancer survivors may partly be psychosocial consequences associated with a chronic illness including a death threat [8]. For functioning scales, cancer survivors in the intervention group may benefit from CBT [21], art and music therapy [20], and supportive-expressive group [17], which seem to positively affect cancer patients' emotional functioning, such as anxiety, depression, coping stress, anger and mood, $[17,19]$. Similarly, MPRRI program provided the cancer survivors with CBT and psycho-education and counselling [17], which focuses on recognizing and changing maladaptive thoughts and behaviors, and focuses on modifying problems with accuracy information from a qualified professional, and result in improving the cognitive functioning. For symptom scales, as noted previously, relaxation training and guided imagery and Guolin Qigong are a series of techniques not only using mental imagery but also physical activities to facilitate relaxation [17], which can potentially contributes to disorder symptoms, such as pain, fatigue and sleep problems $[18,26]$.

This MPRRI includes six different component intervention measures, which are worked in collaboration with each other and have comprehensive effectiveness. The non-pharmacologic supportive strategies or combine self-management with group peer support could promote QoL in cancer survivors related fatigue, meet the cancer patients supportive care needs and psychological distress $[39,40]$. The psycho-education and counseling targets social support, and explains how life events and the social environment affect mood, the influence of mood on social functioning, and provides normalization and validation of participants' experiences and reactions to cancer [41].

In addition, one pronounced improvement in the MPRRI group was physical activity. After the intervention, there were great changes to not only to the proportion of attending physical activity and on the frequency of physical activity per week, but also on physical activity time for both groups. These changes, however, were much more pronounced in the MPRRI group than the WLC group. Historically, clinicians advised cancer patients to rest and to avoid physical activity; however, emerging research on exercise has challenged this recommendation [42]. In 2012, the American Cancer Society (ACS) released guidelines for cancer patients and survivors promoting physical activity to improve cancer outcomes [43], emphasizing regular physical activity of moderate intensity ( $>3 \mathrm{~h} /$ week) is safe and may have improvements in physiology, body composition, physical functions, psychological outcomes [44], quality of life and cancer-related fatigue in cancer progression [45, 46] and survival $[47,48]$. However, fewer than half of cancer survivors are meeting the official guidelines for physical activity [48]. One is that the promotion of physical activity is not integrated into routine clinical practice, which can cause the cancer survivors to overlook physical activity after treatment. This is due to lack of evaluation of the feasibility and effectiveness physical activity and limited resources $[48,49]$. As such, it is crucial to develop and evaluate new strategies to increase access to and maintenance of physical activity and to improve quality of life in this dramatically growing population of cancer survivors.

In this study, we developed a totally new concept and rehabilitation of physical activity-Guolin Qigong, in a real-life setting; it is relaxation training combined with sustainable physical activities.

The MPRRI program is a group-based intervention to facilitate deeply communication among cancer survivors, even beyond this program they can exchange the experience of the course and a new life. Additionally, this program is a multi-focused psychosocial intervention, combining the modern science discipline including psychological components, and traditional Chinese medicine including Guolin Qigong, which is a feasible measure for cancer survivors. As the implementers of this program, the SCRC staffs themselves were also cancer survivors. Their identities were helpful to narrow the psychological gap between themselves and the participants. Moreover, their experience in cancer diagnosis, treatment and rehabilitation can be transferred directly to the participants. Of note, this study supports the feasibility of the MPRRI program in China, which provides a new insight and may be generalizable to other countries and geographical regions.

In our study, the significant changes in some subscales of QoL from the 4-week to 6-month points within followup showed non-continuous progress, especially in symptom domains. Continuity of care should be considered a core element of high-quality primary care in cancer rehabilitation stage after the MPRRI.

\section{Strengths and limitations}

To the best of our knowledge, this is the first study to evaluate the effect of combined supportive-expressive group, guided visualization, cognitive-behavioral therapy, music therapy, psycho-education, and Guolin Qigong on cancer survivors' QoL. While this study has several limitations. First, the results presented in this analysis were based on recruited participants rather than a random sample. There is likely to be selection bias in both groups. For example, these study participants may be 
healthier than is generally the case for patients with cancer. Second, although the proportions of different types of cancer between the two groups showed a reasonably good balance, we did not obtain the data on their specific pathological cancer type with respect to stage or complex clinical treatment, such as stage of cancer (early or late stage), different type of chemotherapy, radiotherapy, surgery or other treatment, or co-morbid chronic diseases. These factors may have an impact on the effectiveness of interventions. Third, because of the multi-component nature of the intervention, it is not possible to conclude which component was truly effective. Additionally, as an exploratory study, many endpoints were analyzed and some reached significance by chance (type I error), which makes it difficult to draw firm conclusions. Fourth, a response shift may have occurred if a patient changed his or her internal reference base of health status over time as a consequence of his or her cancer experience and mask true changes. Fifth, the role of optimism may be a significant issue in this study. Some people always have a positive health response and hide their infirmity or overestimate their true health status. These biases may have had the effect of inflating QoL scores beyond what would otherwise be recorded. Further, the lack of equilibrium mean score of QoL between the two groups at baseline could cause confounding effects and bias. Further studies should focus on changes in patients' life behaviors and the long-term effects of the interventions. More medical data of the cancer survivors in the two groups, such as, the stage of cancer, clinical treatment, co-morbid chronic diseases, can be collected and compared in parallel or stratified analysis can be made at each time points.

\section{Conclusions}

These preliminary results suggest a combined intervention program is both feasible and acceptable intervention for cancer survivors in community settings and is effective in significant improving QoL above (emotional functioning, cognitive functioning and pain) without clinical change.

\section{Abbreviations}

MPRRI: multi-focused psychosocial residence rehabilitation intervention; SCRC: Shanghai Cancer Rehabilitation Club; WLC: waiting-list comparison; QoL: quality of life; EORTC QLQ-C30: European Organization for Research and Treatment Quality of Life Version 3 Questionnaire; CBT: cognitive-behavioral therapy; GHS: global health status; BMI: body mass index; MLGM: multilevel linear growth model; Cls: confidence intervals; GEE: generalized estimating equations; ES: effect sizes; ACS: American Cancer Society.
}

\section{Authors' contributions}

$J Y$ and JW formulated the overarching research goals and aims. XC conceived the study, supervised data collection, interpreted the data, and drafted and revised the manuscript. XG, CS, LS supervised data collection and interpreted $\bigoplus$ the manuscript. ZY supervised data collection and research quality control. All authors read and approved the final manuscript.

\begin{abstract}
Author details
${ }^{1}$ Key Lab of Public Health Safety of Ministry of Education and Key Lab of Health Technology Assessment of Ministry of Health, School of Public Health, Fudan University, No. 130 Dongan RD, Xuhui District, Shanghai Zip code: 200032 , China. ${ }^{2}$ School of Public Health, Shanghai University of Traditional Chinese Medicine, No. 1200 Cailun Rd, Pudong New Area, Shanghai Zip code: 201203, China. ${ }^{3}$ Shanghai Cancer Rehabilitation Center, No. 164 Zhengning Rd 405 Nong, Shanghai Zip code: 200050, China.
\end{abstract}

\section{Acknowledgements}

We thank Shanghai Cancer Rehabilitation Club which provided invaluable resources for field investigation. We thank all staffs and volunteers involved in the acquisition of data. We are grateful to all involved cancer survivors for their open mind to the study and positive attitude to life. In addition, we would like to thank Drs. Drew Nannini and Hui Zuo for their valuable suggestions and revision. This work was supported by Shanghai Public Health Three-year Action Plan Key Discipline Construction Project [Award Number 15GWZK1001]; the National Social Science Foundation of China [Award Number 13CSH076];Shanghai Municipal Commission of Health and Family Planning [Award Number 201440469], and Academic Talent Incubation Program of Basic Medicine School in Shanghai University of Traditional Chinese Medicine (Program Trek). Finally, we would like to thank LetPub (https://www.letpu b.com) for providing linguistic assistance during the revise of this manuscript.

\section{Competing interests}

The authors declare that they have no competing interests.

\section{Availability of data and materials}

Not applicable.

\section{Consent for publication}

Not applicable. The dataset supporting the conclusions of this article will not be available in a public repository because consent/approval was not obtained for the sharing of subject data from participants or the Medical Research Ethics Committee of the School of Public Health, Fudan University.

\section{Ethics approval and consent to participate}

This article does not contain any studies with animals performed by any of the authors. This study was approved by the Medical Research Ethics Committee at Fudan University in Shanghai, China (Protocol Number RB \#2013-04-0450). All clinical investigation was performed according to the principles outlined in the Declaration of Helsinki. Written informed consent was obtained from all participants before treatment.

\section{Funding}

This study was supported by Shanghai Public Health Three-year Action Plan Key Discipline Construction Project [Award Number 15GWZK1001]; the National Social Science Foundation of China [Award Number 13CSH076];Shanghai Municipal Commission of Health and Family Planning [Award Number 201440469], and Academic Talent Incubation Program of Basic Medicine School in Shanghai University of Traditional Chinese Medicine (Program Trek).

\section{Publisher's Note}

Springer Nature remains neutral with regard to jurisdictional claims in published maps and institutional affiliations.

Received: 17 June 2018 Accepted: 24 August 2018

Published online: 06 September 2018

\section{References}

1. Torre LA, Bray F, Siegel RL, Ferlay J, Lortet-Tieulent J, Jemal A. Global cancer statistics, 2012. CA Cancer J Clin. 2015;65:87-108.

2. Chen W, Zheng R, Baade PD, Zhang S, Zeng H, Bray F, et al. Cancer statistics in China, 2015. CA Cancer J Clin. 2016;66(2):115-32. https://doi. org/10.3322/caac.21338. 
3. Chen W, Zheng R, Zeng H, Zhang S, He J. Annual report on status of cancer in China, 2011. Chin J Cancer Res (Chung-kuo yen cheng yen chiu). 2015;27(1):2-12. https://doi.org/10.3978/j.issn.1000-9604.2015.01.06.

4. Thong MSY, Mols F, Stein KD, Smith T, Coebergh JWW. Poll-Franse LVvd. Population-based cancer registries for quality-of-life research. Cancer. 2013;119(S11):2109-23. https://doi.org/10.1002/cncr.28056.

5. McGrath P. Findings from an educational support course for patients with leukemia. Cancer Pract. 1999;7(4):198-204. https://doi.org/10.104 6/j.1523-5394.1999.74006.x.

6. Raijmakers NJH, Zijlstra M, van Roij J, Husson O, Oerlemans S, van de PollFranse LV. Health-related quality of life among cancer patients in their last year of life: results from the PROFILES registry. Support Care Cancer. 2018. https://doi.org/10.1007/s00520-018-4181-6.

7. Bertero C, Eriksson BE, Ek AC. A substantive theory of quality of life of adults with chronic leukaemia. Int J Nurs Stud. 1997;34(1):9-16.

8. Ganz PA. Why and how to study the fate of cancer survivors: observations from the clinic and the research laboratory. Eur J Cancer. 2003;39(15):2136-41.

9. Oberguggenberger A, Hubalek M, Sztankay M, Meraner V, Beer B, Oberacher $\mathrm{H}$, et al. Is the toxicity of adjuvant aromatase inhibitor therapy underestimated? Complementary information from patient-reported outcomes (PROs). Breast Cancer Res Treat. 2011;128(2):553-61. https:// doi.org/10.1007/s10549-011-1378-5.

10. Curran V. "Voices and Faces": a qualitative study of rural women and a breast cancer self-help group via an audio teleconferencing network. 2018.

11. Turner J, Zapart S, Pedersen K, Rankin N, Luxford K, Fletcher J. Clinical practice guidelines for the psychosocial care of adults with cancer. Psycho-oncology. 2005;14(3):159-73. https://doi.org/10.1002/pon.897.

12. Hersch J, Juraskova I, Price M, Mullan B. Psychosocial interventions and quality of life in gynaecological cancer patients: a systematic review. Psycho-oncology. 2009;18(8):795-810. https://doi.org/10.1002/pon.1443.

13. Zheng Y, Huang J, Peng P. Practice on cancer patient care in community in Shanghai. China Cancer. 2010;2:004.

14. Xue C. Study on quality of life among community breast cancer survivors and community-based intervention strategy in Shanghai, Fudan University, 2009.

15. Seegers C, Walker BL, Nail LM, Schwartz A, Mudgett LL, Stephen S. Selfcare and breast cancer recovery. Cancer Pract. 1998;6(6):339-45.

16. Okamura $\mathrm{H}$. Importance of rehabilitation in cancer treatment and palliative medicine. Jpn J Clin Oncol. 2011;41(6):733-8. https://doi. org/10.1093/jjco/hyr061.

17. Jacobsen PB, Jim HS. Psychosocial interventions for anxiety and depression in adult cancer patients: achievements and challenges. CA Cancer J Clin. 2008;58(4):214-30. https://doi.org/10.3322/ca.2008.0003.

18. Jallo N, Ruiz RJ, Elswick RK Jr, French E. Guided imagery for stress and symptom management in pregnant african american women. Evid Based Complement Altern Med (eCAM). 2014;2014:840923. https://doi. org/10.1155/2014/840923.

19. Boehm K, Cramer H, Staroszynski T, Ostermann T. Arts therapies for anxiety, depression, and quality of life in breast cancer patients: a systematic review and meta-analysis. Evid Based Complement Altern Med (eCAM). 2014. https://doi.org/10.1155/2014/103297.

20. Archer S, Buxton S, Sheffield D. The effect of creative psychological interventions on psychological outcomes for adult cancer patients: a systematic review of randomised controlled trials. Psycho-oncology. 2015;24(1):1-10. https://doi.org/10.1002/pon.3607.

21. Garland SN, Carlson LE, Stephens AJ, Antle MC, Samuels C, Campbell TS. Mindfulness-based stress reduction compared with cognitive behavioral therapy for the treatment of insomnia comorbid with cancer: a randomized, partially blinded, noninferiority trial. J Clin Oncol. 2014;32(5):44957. https://doi.org/10.1200/jco.2012.47.7265.

22. Duijts SF, van Beurden M, Oldenburg HS, Hunter MS, Kieffer JM, Stuiver MM, et al. Efficacy of cognitive behavioral therapy and physical exercise in alleviating treatment-induced menopausal symptoms in patients with breast cancer: results of a randomized, controlled, multicenter trial. J Clin Oncol. 2012;30(33):4124-33. https://doi.org/10.1200/jco.2012.41.8525.

23. Lee JY, Park HY, Jung D, Moon M, Keam B, Hahm BJ. Effect of brief psychoeducation using a tablet PC on distress and quality of life in cancer patients undergoing chemotherapy: a pilot study. Psycho-oncology. 2014;23(8):928-35. https://doi.org/10.1002/pon.3503.
24. Jacobsen PB, Wells KJ, Meade CD, Quinn GP, Lee J-H, Fulp WJ, et al. Effects of a brief multimedia psychoeducational intervention on the attitudes and interest of patients with cancer regarding clinical trial participation: a multicenter randomized controlled trial. J Clin Oncol. 2012;30(20):251621. https://doi.org/10.1200/JCO.2011.39.5186.

25. Fong SS, Ng SS, Luk WS, Luk WS, Chung JW, Leung JC, Masters RS. Effects of a 6-month Tai Chi Qigong program on arterial hemodynamics and functional aerobic capacity in survivors of nasopharyngeal cancer. J Cancer Surviv. 2014;8:618-26.

26. Chen Z, Meng Z, Milbury K, Bei W, Zhang Y, Thornton B, Liao Z, et al. Qigong improves quality of life in women undergoing radiotherapy for breast cancer: results of a randomized controlled trial. Cancer. 2013;119:1690-8

27. Aaronson NK, Ahmedzai S, Bergman B, Bullinger M, Cull A, Duez NJ, et al. The European Organization for Research and Treatment of Cancer QLQC30: a quality-of-life instrument for use in international clinical trials in oncology. J Natl Cancer Inst. 1993;85(5):365-76.

28. Fayers PM, Aaronson N, Bjordal K, Groenvold M, Curran D, Bottomley A. EORTC QLQ-C30 scoring manual. 3rd ed. Brussels: European Organisation for Research and Treatment of Cancer; 2001.

29. Wang J, Xie H, Fisher JH. Multilevel models: applications using SAS. Berlin: Walter de Gruyter \& Co.; 2011

30. Cohen J. Statistical power analysis for the behavioral sciences. Hillsdale: L. Erlbaum Associates; 1988.

31. Osoba D, Rodrigues G, Myles J, Zee B, Pater J. Interpreting the significance of changes in health-related quality-of-life scores. J Clin Oncol. 1998;16(1):139-44. https://doi.org/10.1200/jco.1998.16.1.139.

32. Cheng H, Sit JWH, Chan CH, Song WK, Choi KC, Cheng KK. Social support and quality of life among Chinese breast cancer survivors: Findings from a mixed methods study. Eur J Oncol Nurs. 2013;17(6):788-96. https://doi. org/10.1016/j.ejon.2013.03.007.

33. Oechsle K, Goerth K, Bokemeyer C, Mehnert A. Anxiety and depression in caregivers of terminally ill cancer patients: impact on their perspective of the patients'symptom burden. J Palliat Med. 2013;16(9):1095-101. https ://doi.org/10.1089/jpm.2013.0038.

34. Ward S, Donovan HS, Owen B, Grosen E, Serlin R. An individualized intervention to overcome patient-related barriers to pain management in women with gynecologic cancers. Res Nurs Health. 2000;23(5):393405. https://doi.org/10.1002/1098-240X(200010)23:5\%3c393 :AID-NUR6\%3e3.0.CO;2-O.

35. Seah DS, Lin NU, Curley C, Weiner EP, Partridge AH. Informational needs and the quality of life of patients in their first year after metastatic breast cancer diagnosis. J Community Support Oncol. 2014;12(10):347-54. https //doi.org/10.12788/jcso.0077.

36. Roberts KJ, Lepore SJ, Urken ML. Quality of life after thyroid cancer: an assessment of patient needs and preferences for information and support. J Cancer Educ. 2008;23(3):186-91. https://doi.org/10.1080/08858 190802247762.

37. Goss PE, Strasser-Weippl K, Lee-Bychkovsky BL, Fan L, Li J, Chavarri-Guerra $Y$, et al. Challenges to effective cancer control in China, India, and Russia. Lancet Oncol. 2014;15(5):489-538. https://doi.org/10.1016/s1470 $-2045(14) 70029-4$.

38. Ming $X$. Construction and application research of life significance intervention program for terminal cancer patients. The Second Military Medical University, 2013.

39. Wanchai A, Armer JM, Stewart BR. Nonpharmacologic supportive strategies to promote quality of life in patients experiencing cancer-related fatigue: a systematic review. Clin J Oncol Nurs. 2011;15(2):203-14. https:// doi.org/10.1188/11.cjon.203-214.

40. Chambers SK, Newton RU, Girgis A, Nielsen L, Lepore S, Mihalopoulos C, et al. Living with prostate cancer: randomised controlled trial of a multimodal supportive care intervention for men with prostate cancer. BMC Cancer. 2011;11:317. https://doi.org/10.1186/1471-2407-11-317.

41. Badger TA, Segrin C, Figueredo AJ, Harrington J, Sheppard K, Passalacqua $S$, et al. Who benefits from a psychosocial counselling versus educational intervention to improve psychological quality of life in prostate cancer survivors? Psychol Health. 2013;28(3):336-54. https://doi. org/10.1080/08870446.2012.731058.

42. Schmitz KH, Courneya KS, Matthews C, Demark-Wahnefried W, Galvao DA, Pinto BM, et al. American College of Sports Medicine roundtable 
on exercise guidelines for cancer survivors. Med Sci Sports Exerc. 2010;42(7):1409-26. https://doi.org/10.1249/MSS.0b013e3181e0c112.

43. Kushi LH, Doyle C, McCullough M, Rock CL, Demark-Wahnefried W, Bandera EV, et al. American Cancer Society Guidelines on nutrition and physical activity for cancer prevention: reducing the risk of cancer with healthy food choices and physical activity. CA Cancer J Clin. 2012;62(1):30-67. https://doi.org/10.3322/caac.20140.

44. Fong DY, Ho JW, Hui BP, Lee AM, Macfarlane DJ, Leung SS, et al. Physical activity for cancer survivors: meta-analysis of randomised controlled trials. BMJ (Clinical research ed). 2012;344:e70. https://doi.org/10.1136/bmj.e70.

45. Tomasone JR, Zwaal C, Kim G, Yuen D, Sussman J, Segal R, et al. Moving guidelines into action: a report from cancer care Ontario's event let's get moving: exercise and rehabilitation for cancer patients. Curr Oncol. 2017;24(1):e65-74. https://doi.org/10.3747/co.24.3422.

46. Segal R, Zwaal C, Green E, Tomasone JR, Loblaw A, Petrella T. Exercise for people with cancer: a systematic review. Curr Oncol. 2017;24(4):e290315. https://doi.org/10.3747/co.24.3619.
47. Dieli-Conwright CM, Mortimer JE, Schroeder ET, Courneya K, DemarkWahnefried W, Buchanan TA, et al. Randomized controlled trial to evaluate the effects of combined progressive exercise on metabolic syndrome in breast cancer survivors: rationale, design, and methods. BMC Cancer. 2014;14:238. https://doi.org/10.1186/1471-2407-14-238.

48. Bruun DM, Bjerre E, Krustrup P, Brasso K, Johansen C, Rorth M, et al. Community-based recreational football: a novel approach to promote physical activity and quality of life in prostate cancer survivors. Int J Environ Res Public Health. 2014;11(6):5567-85. https://doi.org/10.3390/ ijerph110605567.

49. Khan KM, Thompson AM, Blair SN, Sallis JF, Powell KE, Bull FC, et al. Sport and exercise as contributors to the health of nations. Lancet. 2012;380(9836):59-64. https://doi.org/10.1016/s0140-6736(12)60865-4.
Ready to submit your research? Choose BMC and benefit from:

- fast, convenient online submission

- thorough peer review by experienced researchers in your field

- rapid publication on acceptance

- support for research data, including large and complex data types

- gold Open Access which fosters wider collaboration and increased citations

- maximum visibility for your research: over 100M website views per year

At BMC, research is always in progress.

Learn more biomedcentral.com/submissions 